\title{
Cold and compression in the management of musculoskeletal injuries and orthopedic operative procedures: a narrative review
}

This article was published in the following Dove Press journal:

Open Access Journal of Sports Medicine

6 July 2010

Number of times this article has been viewed

\section{Jon E Block}

Jon E Block, PhD., Incorporated, San Francisco, CA, USA
Correspondence: Jon E Block 2210 Jackson Street, Suite 40I, San Francisco, CA 94I I5, USA

$\mathrm{Tel}+$ I 4157757947

Fax + I 4159280765

Email: jonblock@jonblockphd.com
Abstract: Cold and compression are routinely applied immediately after acute injury or following surgery to alleviate pain, reduce swelling and speed functional recovery. The objective of this literature review is to describe the published clinical findings regarding combined cold and compression therapy in the management of musculoskeletal injuries and after orthopedic operative procedures. Of 33 potential articles triaged, the findings of 21 randomized controlled trials were assessed and summarized. The findings reported by these 21 studies were largely subjective pain outcomes and, to a lesser degree, swelling and range of motion, and were inconsistent and divergent, making it difficult to recommend the most appropriate, effective clinical application of cold and compression. Further, 18 of the 21 reported studies evaluated cold and static compression, where the extent and duration of the compression was not uniform within or across studies. Operative procedures may offer a more controlled environment for rigorous investigations. However, such studies must be powered sufficiently to account for variations in surgical procedure that could affect outcomes. More uniform operative procedures, such as total knee arthroplasty, represent a well circumscribed intervention for studying the clinical utility of cold compression therapy because the operative technique is standardized, surgical tissue damage is extensive, intraoperative blood loss is high, and post-operative edema and pain are severe. Findings from randomized controlled trials of knee arthroplasty generally showed cold compression therapy provides better outcomes such as pain relief than alternative interventions. While the effects of cold and static compression are clearly better than no treatment, they do not appear to be directly additive.

Keywords: cryotherapy, injury

\section{Introduction}

The use of bags of crushed ice or cold gel packs secured to various anatomical sites with bandaging or elastic wraps is a common observation in locker rooms of athletic facilities everywhere. In this setting, cryotherapy with some degree of concomitant static compression is routinely applied immediately after an acute musculoskeletal injury (eg, ankle sprain, muscle pull) or as prophylaxis for chronic orthopedic sports problems (eg, tennis elbow). Indeed, the long held dictum among physical therapists in the management of soft tissue trauma remains protection, rest, ice, compression and elevation. ${ }^{1}$ Because cold compression therapy directly addresses the swelling, inflammation and pain associated with these injuries, this modality has been extended to the post-operative management of a variety of orthopedic procedures (eg, knee arthroplasty) where surgically-induced tissue damage results in a similar but often more severe set of symptoms. ${ }^{2,3}$ 
Because the benefits of cold compression therapy diminish with time, this intervention is thought to be most effective if applied almost immediately after injury or at the conclusion of an operative procedure. Consequently, controlled trials of acute athletic- or trauma-related musculoskeletal injuries have been few, challenging to conduct and the findings difficult to interpret. ${ }^{4-7}$ Thus, treatment remains somewhat empirical and inexact. On the other hand, the operative setting provides a more controlled environment for evaluating the role of cold compression in the management of post-surgical edema, pain and return to function. As a result, controlled trials have better methodological quality and findings may have improved veracity. ${ }^{8}$ However, reports of such studies in the literature to date appear to be conflicting.

\section{Rationale for cold compression therapy}

The local application of cold suppresses the metabolic rate of the immediately surrounding soft tissue. This decrease in tissue metabolism is associated with a reduction in enzymatic activity, preventing tissue damage caused by hypoxia. ${ }^{9,10}$ Local hypothermia induces vasoconstriction and lowers microcirculation by more than $60 \%$, an effect that can persist for up to 30 minutes after cessation of cooling. ${ }^{11-13}$ Coldinduced vasoconstriction reduces extravasation of blood into surroundings tissues, local inflammation and edema production. ${ }^{14}$ The amelioration of pain associated with the direct application of cold to injured tissue is, in part, related to the reduction in edema formation as well as to decreases in motor and sensory nerve conduction. ${ }^{1}$

A reduction in blood flow and swelling also can be achieved with compression by facilitating translocation of edema away from the site of injury and toward proximal noncompressed tissues where it can be resolved more efficiently by the lymphatic system. ${ }^{15-17}$ Importantly, the addition of cold to compression increases the rate, magnitude and depth of temperature reduction ${ }^{18,19}$ as well as the speed of lymph evacuation. ${ }^{15}$

\section{Data sources}

Articles published in English-language journals regarding the role of cold compression therapy in the management of musculoskeletal injuries and orthopedic operative procedures were identified using online search methods previously described by Bleakley et $\mathrm{al}^{4}$ and Hubbard et al. ${ }^{6}$ The PubMed ${ }^{\mathrm{TM}}$ database was searched iteratively starting in 1976 using the following key words: cryotherapy, cold, compression, and ice coupled with numerous limiting descriptors such as injury, edema, pain, and arthroplasty. The bibliographies of all articles were examined to identify other potentially relevant study reports. All online searches were updated through September 2009 and included only reports of randomized controlled trials. Articles were included in this literature review if the methods section indicated that at least one randomly-assigned treatment consisted of cryotherapy combined with compression. Treatment modalities could comprise dedicated cold compression devices or crushed ice and cold packs secured with elastic wraps or bandages providing concomitant mild to moderate compression. Of 33 potential articles triaged, 21 were identified that met the selection criteria including two articles on ankle sprains, ${ }^{20,21}$ eight on knee ligament repair, ${ }^{8,10,22-27}$ seven on total knee arthroplasty,,$^{2,28-33}$ and four on miscellaneous procedures including ankle fractures ${ }^{34,35}$ and shoulder surgery. ${ }^{36,37}$ The background characteristics and key clinical findings from each article were abstracted in narrative form and presented by indication for use and date of publication.

\section{Clinical synthesis}

\section{Ankle sprains}

Sloan et $\mathrm{al}^{20}$ randomly assigned 143 consecutive acute ankle injury patients to cold compression treatment or compression only. Patient background characteristics were comparable between treatment groups with an overall median age of 24 years, $21 \%$ female and 17.5 hours since time of injury. Athletic injuries accounted for $53 \%$ of cases, and approximately $50 \%$ of patients were judged to have severe or very severe injuries, defined as unable to bear weight. Continuous moderate compression was provided for all patients with an elastic support (ProSport, Seton Ltd., Oldham, UK). Experimental patients received a single 30 minute application of cryotherapy with a freon-cooled anklet device (Cryopac, Cryomed Corp., Princeton, NJ, USA) and control patients received a sham device that did not provide cooling. The study was described as double-blind but the adequacy of blinded randomization and treatment allocation concealment were not reported.

Clinical assessments made at seven days post-injury demonstrated a modest difference between groups in favor of the experimental cold compression treatment: $46 \%$ versus $40 \%$ amelioration of soft tissue swelling ( $P=0.07$ ), $88 \%$ versus $79 \%$ in injury severity improvement $(P=0.15), 36 \%$ versus $29 \%$ in ability to bear weight $(P=0.64)$. No differences were observed between groups in range of motion and pain relief.

Wilkerson and Horn-Kingery ${ }^{21}$ conducted a small study of 34 patients (18\% female, mean age: $20.4 \pm 1.8$ years) 
with acute ankle sprains randomly assigned to treatment with either uniform compression $(n=12)$, focal compression $(n=12)$ or focal compression $(n=10)$ with concurrent cryotherapy using a frozen liquid-filled U-shaped device (Aircast Cryo/Strap, Aircast Inc, Summit, NJ, USA). Uniform compression was provided by elastic tape and focal compression provided by the Cryo/Strap device. Patients in the compression only groups also received ice packs applied directly to the skin of the injured ankle for 20-30 minutes at least once per day during the acute phase of injury. Subjects who received focal compression recovered higher levels of ankle function earlier than those receiving uniform compression. However, the addition of concurrent cryotherapy did not appear to offer supplementary benefit, although results are confounded by ice pack administration in the compression only groups and the small sample size of the study.

\section{Knee ligament repair}

Cohn et $\mathrm{al}^{24}$ evaluated 54 consecutive patients having arthroscopically-assisted anterior cruciate ligament (ACL) reconstruction. Twenty six patients (9 of 26 [35\%] female, mean age: 23 years) were randomized to treatment with a $50^{\circ} \mathrm{F}$ thermal blanket device (ThermoTemp Inc, Tampa, FL, USA) providing mild concomitant compression continuously at the knee for four days, and 28 patients (13 of 28 [46\%] female, mean age: 25 years) received standard of care consisting of a bag of ice applied to the knee while in the recovery room only. Patients treated with cold compression required 53\% less injectable meperidine and $67 \%$ less oral hydroxyzine than control patients ( $P<0.01$ for both comparisons). Cold compression patients, on average, also made the conversion from injectable to oral pain medications 1.2 days sooner than controls. The mean duration of hospitalization was the same for both study groups (3.5 vs 3.5 days).

Schroder and Passler ${ }^{8}$ evaluated 44 patients undergoing ACL reconstruction with respect to post-operative swelling, range of motion, pain, analgesic requirements and return to function. Twenty one patients (6 of 21 [29\%] female, mean age: 25 years) were randomized to continuous cold compression treatment with the CryoCuff device (Aircast Inc, Summit, NJ, USA), and 23 patients (5 of 23 [35\%] female, mean age: 24 years) received an ice bag three times per day for the length of their hospitalization. All patients were hospitalized for 14 days and had clinical assessment performed on days 1, 2, 3, 6, 14 and 28. Standardized Noyes functional knee scores were also obtained after 12 weeks of follow-up.

Patients treated with cold compression had significantly greater range of motion on all post-operative days $(P<0.02$ for all comparisons). There was a general trend of lower average pain scores among cold compression patients at all follow-up intervals, with statistical significance $(P=0.01)$ reached on the 6 th post-operative day. The mean functional knee scores were significantly higher in patients treated with cold compression compared to controls (90 vs $82, P=0.03$ ) after three months of follow-up.

Brandsson et $\mathrm{al}^{23}$ randomized 50 consecutive patients (19 of 50 [38\%] female, median age: 26 years) undergoing arthroscopic ACL reconstruction to one of three treatment groups: CryoCuff device plus an intraoperative injection of physiologic saline $(n=20)$, CryoCuff device plus an intraoperative injection of morphine and bupivacaine $(n=20)$, or an intraoperative injection of physiologic saline $(\mathrm{n}=10)$. Visual analog scale (VAS) pain severity scores and analgesic requirements were recorded at multiple time points through 48 hours post-operatively.

Mean pain scores were consistently and significantly lower in the two groups using the CryoCuff device compared to the placebo group at all follow-up intervals. The addition of the injectable narcotics intraoperatively provided additional pain relief at both 24 and 48 hours. Analgesic requirements also were significantly lower among patients using the CryoCuff device and, again, even more so in those receiving an intraoperative injection of narcotics.

Konrath et $\mathrm{al}^{27}$ evaluated 100 consecutive patients scheduled for arthroscopic ACL reconstruction randomized to one of four treatment groups: a Polar Care 500 pad device (Breg Inc, Vista, CA, USA) secured with an elastic wrap set at $40^{\circ}$ to $50^{\circ} \mathrm{F}(\mathrm{n}=27)$, the same device regimen set at $70^{\circ}$ to $80^{\circ} \mathrm{F}(\mathrm{n}=23)$, a bag of crushed ice $(\mathrm{n}=23)$, or no treatment $(n=27)$. All data in this study were collected prior to discharge. Despite significantly lower skin temperatures recorded with the cryotherapy pad and crushed ice, no significant differences were noted across treatment groups for length of hospitalization, range of motion, use of pain medications or drainage output.

Edwards et $\mathrm{al}^{26}$ reported results similar to those of Konrath and coworkers. ${ }^{27}$ In the former study, 71 patients having ACL surgery were randomly assigned to one of three treatments: CryoCuff device ( 8 of 26 [31\%] female, mean age: 29 years), CryoCuff device set at room temperature (4 of 21 [19\%] female, mean age: 26 years), or no treatment (9 of 24 [38\%] female, mean age: 28 years). No significant differences were found 48 hours post-operatively across treatment groups for blood loss as measured from the intraarticular drain before removal, analgesic requirements, range of motion or VAS pain scores. 
Barber et a ${ }^{22}$ randomized 100 patients having ACL reconstruction to a continuous flow cold compression device (Orthopedic Technology, Tracy, CA, USA; Aircast Inc., Summit, NJ, USA) (17 of 51 [33\%] female, mean age: 34 years) or no treatment ( 9 of 49 [18\%] female, mean age: 34 years) for 3 days post-operatively. Pain severity (VAS and Likert scales) was measured daily for one week postoperatively. VAS pain scores were $25 \%$ higher in the control group on the 1 st post-operative day, reaching borderline statistical significance $(P=0.06)$; thereafter they converged during one week of follow-up. On each post-operative day through one week, use of analgesics was always lower among patients treated with cold compression $(P=0.01)$. A physical examination was performed at one week post-operatively. Knee flexion measurements favored cold compression treatment, with borderline significance $\left(88^{\circ}\right.$ vs $\left.77^{\circ} \mathrm{F}, P=0.06\right)$, although extension and swelling were not different across treatment groups. The report concluded that compressive cryotherapy was beneficial in the reduction of pain medication use.

Dervin et $\mathrm{al}^{25}$ examined the effects of cold compression versus compression alone in 78 patients having endoscopic ACL surgery. Forty patients (13 of 40 [33\%] female, mean age: 31 years) were randomized to CryoCuff therapy and 38 patients (11 of 38 [29\%] female, mean age: 27 years) received the same device set at room temperature and followed until hospital discharge. No significant differences were noted with regard to total wound drainage (335 vs $348 \mathrm{~mL}$ ), VAS pain scores at 24 hours ( $3.0 \mathrm{vs} 2.5$ ), analgesic requirements ( 0.37 vs $0.35 \mathrm{mg} / \mathrm{kg}$ morphine), or duration of hospitalization (60 vs 55 hours).

Ohkoshi et a ${ }^{10}$ conducted a small study of 21 patients (11 of 21 [52\%] female, mean age: 22 years) having arthroscopic ACL repair. All patients had an elastic wrap applied post-operatively to provide mild compression, and were randomized equally to one of three additional cold treatments: cryotherapy at $41^{\circ} \mathrm{F}$, cryotherapy at $51^{\circ} \mathrm{F}$, or no cold treatment and followed for 48 hours. For patients receiving cryotherapy, The Icing System 2000 (Nippon Sigmax Co, Tokyo, Japan) was placed on the anterior surface of the knee. The patients having $51^{\circ} \mathrm{F}$ cold therapy had significantly lower mean VAS pain scores, reflecting the most severe pain during 48 hours post-surgery, than either the patients having $41^{\circ} \mathrm{F}$ cold therapy $(3.5$ vs $7.7, P<0.05)$ or the control group ( 3.5 vs $6.6, P<0.05$ ). Control group patients also had a significantly greater mean number of doses of analgesics than the $10^{\circ} \mathrm{C}$ cold therapy patients $(0.7$ vs $1.5, P<0.05)$, but not patients treated at $41^{\circ} \mathrm{F}(1.25$ vs $1.5, P=\mathrm{ns})$. Lastly, mean blood loss suctioned over 48 hours post-surgery was significantly lower for $41^{\circ} \mathrm{F}$ cold therapy patients than controls (52 vs $98 \mathrm{~mL}, P<0.01)$, but not between $51^{\circ} \mathrm{F}$ cold therapy patients and controls ( $78 \mathrm{vs} 98 \mathrm{~mL}, P=\mathrm{ns}$ ).

\section{Total knee arthroplasty}

Levy and Marmar ${ }^{30}$ evaluated blood loss, pain relief and range of motion in 80 consecutive unilateral and 10 bilateral total knee arthroplasty patients. Of the 80 unilateral cases, 40 patients (33 of 40 [83\%] female, mean age: 74 years) were randomized to postoperative cold compression treatment with the CryoCuff device and 40 patients (32 of 40 [80\%] female, mean age: 73 years) to mild compression with an ACETM wrap. (Becton Dickinson, Franklin Lakes, NJ, USA). For bilateral cases, the second knee was selected for cold compression therapy in all patients. This was done to avoid contamination of the sterile field, because the second knee was opened while the first knee was being closed.

All measures of intra- and post-operative blood loss favored the experimental treatment. For example, the average calculated total body blood loss in the experimental and control groups was $1298 \mathrm{~mL}$ and $1908 \mathrm{~mL}$, respectively $(P<0.001)$. Extravasation of blood into soft tissues averaged $744 \mathrm{~mL}$ in those knees treated with cold compression compared to $1101 \mathrm{~mL}$ in control knees $(P<0.001)$. Morphine administration was significantly $(P<0.05)$ less in the experimental group and this was reflected in the VAS pain severity scores. For the experimental and control groups, mean pain scores were 6.6 versus 5.8 pre-operatively $(P=\mathrm{ns})$, 7.4 versus 7.8 on post-operative day one $(P=\mathrm{ns}), 5.9$ versus 7.4 on day two $(P<0.01)$, and 5.6 versus 6.9 on day three $(P<0.05)$, respectively. Total knee range of motion was similar between experimental and control groups prior to surgery $\left(86^{\circ}\right.$ vs $\left.88^{\circ}, P=\mathrm{ns}\right)$, but favored cold compression therapy after 14 days $\left(77^{\circ}\right.$ vs $\left.65^{\circ}, P<0.01\right)$.

Healy et $\mathrm{al}^{29}$ compared two different modes of cold compression in 76 patients (105 knees) undergoing primary total knee arthroplasty with respect to range of motion, swelling, wound drainage, and narcotic requirements. Fifty knees were randomly allocated to treatment with the CryoCuff device and 55 knees were treated with an ACE compression wrap and crushed ice pack. Post-operative follow-up evaluations were undertaken at three intervals: 2 to 4 days, 7 to 14 days, and 4 to 6 weeks. Both groups showed similar levels of improvement over baseline, but there were no notable or statistically significant differences between treatment groups for any outcome evaluated at any interval through six weeks of postoperative follow-up. However, the potential for meaningful 
comparisons of functional endpoints as measured in this study may have been compromised by the wide time window in which measurements were taken (eg, day seven evaluation could be quite different if taken on day 14, instead).

Scarcella and Cohn ${ }^{32}$ studied 24 total knee arthroplasty patients (mean age: 67 years) treated in the immediate postoperative period with the ThermoTemp thermal blanket device providing cold therapy and mild concomitant static compression. One half of the cases were randomly assigned to the cold therapy unit set at $50^{\circ} \mathrm{F}$, and one half the cases to the unit set at $70^{\circ} \mathrm{F}$. Patients were blinded to treatment group assignment and had cryotherapy applied to the operative site until discharge. The post-operative hospital stay was 1.5 days shorter ( 8.6 vs 10.1 days, $P=0.19$ ) and the time to independent ambulation was achieved one day sooner (4.6 vs 5.7 days, $P=0.08$ ), on average, for patients receiving cold therapy compared to controls. However, no significant differences were observed between study groups for range of motion $\left(73^{\circ}\right.$ vs $\left.77^{\circ}\right)$ or narcotic usage ( $4.8 \mathrm{vs} 4.8 \mathrm{mg} / \mathrm{kg}$ meperidine). However, range of motion was only measured at discharge, a time point too early to be meaningful in this setting. Additionally, because of the relatively small sample size, this study was likely underpowered to demonstrate significant differences even though trends favored cold compression therapy.

Webb et $\mathrm{al}^{33}$ enrolled 31 patients undergoing unilateral and 9 patients having bilateral total knee arthroplasty procedures to evaluate the effectiveness of cold compression therapy post-operatively on blood loss, pain, swelling and range of motion. Random treatment allocation consisted of application of the CryoCuff cold compression device or a wool and crepe dressing. Measurements were taken at three post-operative intervals: day five, six weeks, and three months. Swelling was assessed by the same examiner throughout and measured at a point $2 \mathrm{~cm}$ proximal to the patella. The mean blood loss through suction drainage was significantly less from knees receiving cold compression therapy (982 vs $768 \mathrm{~mL}, P<0.05$ ) and a higher proportion of these patients did not require transfused blood post-operatively $(P=0.05)$. Mean opiate requirements also were lower among experimental patients ( 0.57 vs $0.71 \mathrm{mg} / \mathrm{kg} / 48$ hours, $P<0.01)$. Mean post-operative VAS pain severity scores favored cold compression treatment (5.8 vs 4.5, $P<0.05$ ). There were no significant differences detected between treatment groups for swelling or range of motion through three months of follow-up.

Gibbons et al ${ }^{28}$ randomized 60 knee arthroplasty patients equally to either cold compression treatment with the CryoCuff device for a minimum six hours per day (19 of 30 [63\%] female, mean age: 70 years) or a modified Robert Jones bandage providing firm static compression (16 of 30 [53\%] female, mean age: 71 years) at the operative site. All patients were followed for 10 days post-operatively. Blood loss was recorded by the drainage in the suction tube. Morphine use was captured for the first 48 hours, and oral analgesics were recorded over the entire 10 day period. VAS pain scores were recorded on alternate days: one, three, five, seven, and day nine. Range of motion was measured at 10 days post-operatively.

Mean blood loss was significantly lower among patients receiving cold compression treatment (720 vs $1200 \mathrm{~mL}$, $P<0.05)$. However, the addition of cryotherapy to compression did not result in significant differences between groups with respect to range of motion, VAS pain scores or analgesia requirements.

Morsi $^{31}$ studied the effects of cold compression therapy in 30 patients, all having staged bilateral total knee arthroplasty. In all cases, the first operated knee had a continuous flow cold compression device applied postoperatively and the second knee, operated upon 6 weeks later, had no cold or compressive treatment. Pain scores and analgesic requirements were evaluated at daily intervals for the initial 6 days postoperatively, whereas range of motion was evaluated weekly for 6 weeks.

Mean post-operative VAS pain severity scores favored knees treated with cold compression ( 4.2 vs $6.3, P<0.001)$ and total mean analgesic requirements were greater during the second (control) operation (950 vs $1400 \mathrm{mg}$, $P<0.01)$. Average blood loss from suction drainage (503 vs $810 \mathrm{~mL}, P<0.001)$, total body blood loss (1214 vs $1867 \mathrm{~mL}, P<0.001$ ), extravasation of blood into soft tissue ( 741 vs $1191 \mathrm{~mL}, P<0.001$ ), and the proportion of patients requiring blood transfusions (20\% vs 57\%, $P<0.05)$ all favored cold compression treatment. Lastly, the average range of motion was $68^{\circ}$ and $54^{\circ}$ in experimental and control knees, respectively, one week after surgery $(P<0.01)$ without notable or statistically significant differences at 6 weeks.

Kullenberg et $\mathrm{al}^{2}$ randomized 86 consecutive unilateral total knee arthroplasty patients to either cold compression treatment with the CryoCuff device ( $n=41$, mean age: 68 years) or standard epidural analgesia $(n=45$, mean age: 69 years) for three days post-operatively. Total morphine requirements were generally lower after cold compression treatment compared to standard of care. At discharge, range of motion averaged $75^{\circ}$ in the cold compression group and 
$63^{\circ}$ in the control group $(P=0.002)$. This trend in favor of cold compression was maintained at the final three week follow-up interval $\left(99^{\circ}\right.$ vs $\left.88^{\circ}, P=0.005\right)$. There was a significant reduction in the mean length of hospital stay between patients randomized to cold compression (4.8 days) and controls (6.2 days) $(P<0.001)$.

\section{Miscellaneous procedures}

Stockle et $\mathrm{al}^{35}$ compared the effectiveness of three treatment modalities in reducing acute post-traumatic and post-operative swelling following foot and ankle trauma. Sixty patients, 48\% (29 of 60) with ankle fractures, were stabilized in a split plaster cast and randomized to receive either cool packs ( $n=20$, mean age: 33.1 years), continuous cryotherapy with the Polar Care device $(n=20$, mean age: 31.9 years), or intermittent impulse compression with the A-V Impulse System (Novamedix Services Ltd, Andover, Hants, UK) ( $n=20$, mean age: 36.8 years $)$ without concomitant cryotherapy. Patients randomized to cool pack treatment had the pack changed four times per day and fixed around the swollen area with an elastic dressing providing static compression. Patients receiving continuous cryotherapy had a flexible cool cuff wrapped around the swollen area with a continuous flow of ice water. Lastly, patients treated with impulse compression used a foot pump device that simulated weight-bearing by intermittently compressing and stretching the venae comitantes of the lateral plantar artery. With this device, an under the foot air pad inflates every 20 seconds, squeezing and flattening the plantar arch resulting in the rapid evacuation of 20 to $30 \mathrm{~mL}$ of blood from the plantar venous plexus.

After 24 hours of treatment, there was a $47 \%$ reduction in swelling with the impulse compression device, $33 \%$ with continuous cryotherapy and $17 \%$ with cool packs. After four days of post-operative treatment, the impulse system reduced swelling by $74 \%$ versus $70 \%$ with continuous cryotherapy and $45 \%$ with cool packs. All of these comparisons reached statistical significance in favor of either impulse compression or continuous cryotherapy over standard use of cool packs with mild static compression.

Speer et $\mathrm{al}^{37}$ reported the results of pain outcomes in 50 patients equally randomized to cold and mild static compression or no treatment control following a heterogeneous mix of shoulder surgeries including anterior shoulder stabilization, rotator cuff repair, or total shoulder replacement. The experimental treatment consisted of the CryoCuff device, a closed, water pressurized bladder system that is held snugly to the shoulder. Baseline characteristics were similar between patients randomized to cryotherapy (6 of 25 [24\%] female, mean age: 36.9 years) and control (8 of 25 [32\%] female, mean age: 39.4 years). All outcomes were evaluated by standard $10 \mathrm{~cm}$ VAS on the first postoperative day and at the time of suture removal (day 10).

On the initial day postoperatively, there was a significant difference favoring cryotherapy in mean pain severity scores (3.1 vs $5.7, P=0.001)$, frequency of shoulder pain (3.5 vs $5.3, P=0.008)$, comfort in lying in bed (3.1 vs $4.7, P=0.02$ ), ease with sleep (3.0 vs $4.9, P=0.006)$, and the perceived need for narcotics (6.6 vs $8.5, P=0.02$ ). Significant differences in outcomes in favor of cryotherapy were generally maintained at day 10 including pain during rehabilitation exercises (3.2 vs 5.5, $P=0.001)$ and perceptions of swelling (7.6 vs $18.7, P=0.01$ ).

In a follow-up study by members of the same research group, Singh et $\mathrm{al}^{36}$ evaluated similar clinical outcomes (ie, VAS) after both open and arthroscopic shoulder procedures. Thirty two patients were randomly assigned continuous cryotherapy with mild compression compared to 32 no treatment controls. Open and arthroscopic procedures were equally distributed between study groups. The Polar Care device, a continuous cryotherapy shoulder pad, was used in the experimental group.

Comparisons between groups always favored treatment with cold compression and statistically significant differences were demonstrated after the initial post-operative day for comfort $(P=0.001)$, restfulness $(P=0.004)$, and pain frequency $(P=0.01)$ among patients undergoing open surgical procedures. During days 7 through 21, cryotherapy patients reported larger reductions in pain severity and frequency, as well as less pain during shoulder rehabilitation, than control patients regardless of whether the procedure was open or arthroscopic. For example, by day 14, cryotherapy patients treated arthroscopically demonstrated a significant and marked reduction in pain severity $(P=0.04)$.

Mora et $\mathrm{al}^{34}$ enrolled 24 patients with closed ankle fractures requiring open reduction and internal fixation in a preoperative study of edema. Patients were randomized to mild pulsatile cold compression (3 of 11 [27\%] female, mean age: 29 years) or a standard long leg cast (3 of 13 [23\%] female, mean age: 33 years). Patients in the experimental group were placed into a CryoCuff compression device combined with an AutoChill pump (Aircast Inc., Summit, NJ, USA) providing intermittent pulsatile compression. All patients had circumferential measurements of both ankles performed every 24 hours for three days prior to surgery to evaluate edema resolution. The median decrease of circumference in 
the experimental group compared to the control group was $0.5 \mathrm{~cm}$ versus $0.1 \mathrm{~cm}$ at 24 hours $(P=0.005), 0.9 \mathrm{~cm}$ versus $0.4 \mathrm{~cm}$ at 48 hours $(P<0.001)$, and $1.2 \mathrm{~cm}$ vs $0.5 \mathrm{~cm}$ at 72 hours $(P=0.009)$. The ratio of the decrease in circumference relative to the circumference of the normal ankle was significantly higher in the pulsatile cold compression group compared to the control group at all time points $(P \leq 0.03$ for all comparisons). These findings suggest a benefit in reducing edema associated with the use of cryotherapy with pulsatile compression, although it is unknown whether this modality provided additional benefit over cold and static compression.

\section{Discussion}

The studies reviewed here are representative of the body of literature available to clinicians and other decision-makers seeking evidence-based support for therapeutic choices regarding treatment recommendations for post-operative orthopedic rehabilitation. Unfortunately, the studies are not uniform in their choices of experimental and control groups, study duration, sample size or surgical procedure, rendering the "evidence" diluted.

Eighteen of the 21 studies reviewed used cold with static compression as one of the experimental groups (some studies had 3 study arms). Two studies ${ }^{21,35}$ used some modified compression modality that was not static and one used intermittent pneumatic compression. ${ }^{34}$ Furthermore, some studies compared cold and static compression to compression only or to no treatment at all, while others compared specific cold compression modalities to an ice bag with a compression bandage.

Almost without exception, the use of cold compression therapy following either acute musculoskeletal injury or orthopedic surgery results in improved clinical outcomes compared to no treatment. However, results of studies comparing cold compression therapy with either modality alone were more equivocal and difficult to interpret. While some authors ${ }^{33}$ have suggested that the effects of cold and compression are additive, findings from the studies reviewed herein suggest that gains derived from the combined treatment of cold and static compression are only marginally greater than either therapy alone. This may be due to the varying methodologies of the studies, the differing modalities employed, or the fact that in many studies compressive dressings were often applied in multiple layers over the injury site without a standardized amount of pressure, potentially mitigating the cooling effect of the external cryotherapy modality and preventing adequate metabolic reduction.
Previous reviews ${ }^{4,6,7}$ have attempted to disentangle the effects of cold and static compression to elucidate the independent contributions of each. The task has been daunting. Indeed, Bleakley et $\mathrm{al}^{4}$ in an effort to calculate quantitative effect sizes for clinical outcomes from 28 study groups, found that adequate data were provided for only three (11\%) study groups for function, $18(64 \%)$ for pain, $10(36 \%)$ for swelling, and $11(39 \%)$ for range of motion. Additionally, because of different indications for use, types of treatment modalities and clinical heterogeneity, it was impossible to pool results in a meaningful way with respect to some index of improvement such as the minimal clinically important difference.

Previous reviews also have noted the relatively poor methodological quality of randomized trials of cold and compression therapy, and this has confounded interpretation. ${ }^{4,6,7}$ The low scores achieved on standardized methodology checklists for these trials are almost uniformly due to the difficulty involved in blinding study subjects. Adequate study blinding is heavily weighted in these checklists, as the effects of lack of treatment allocation concealment are well described ${ }^{38}$ and are particularly potent in studies involving subjective patient reported outcomes such as pain. ${ }^{39}$ It is unclear whether this methodological shortcoming can be overcome in future trials of cold compression therapy.

Two studies ${ }^{20,32}$ reviewed claim to have blinded subjects to random treatment assignment, potentially improving the methodological quality of these reports which both indicate an absence of differences in clinical outcomes between the study groups. However, the adequacy of the blinding procedure was not reported.

Until there is a definitive trial of the clinical effects of a defined cryotherapy method and a defined compression modality, the real benefit and therefore the clinical application of generic cold compression therapy will remain unclear and evidence-based decisions about its use poorly guided. Meanwhile, cryotherapy modalities continue to evolve. The current impetus and likely future direction of cold compression therapy is in the use of stand alone, dedicated devices that provide both modalities in a controlled, regulated and quantifiable manner. This mitigates the possibility of excessive cooling causing tissue damage that can occur with direct ice application. ${ }^{40}$ These devices also remove the inherent random and widely-varying intensity of pressure associated with bandages and elastic wraps. Emerging evidence suggests that cyclic application of external pressure with intermittent pneumatic compression provides increased arterial blood flow, decreased venous pressure, reduced venous stasis and increase the ingrowth of neurovascular tissue. ${ }^{16,41}$ 
Two studies reviewed examined the preliminary effectiveness of pulsatile compression on clinical outcomes and noted encouraging results. ${ }^{34,35}$ Devices that incorporate cold and intermittent compression in a controlled fashion will likely be the best option post-operatively, providing the patient with the maximum degree of comfort and the shortest time to functional recovery.

Studies of total knee arthroplasty, in particular, appear to offer an excellent model for evaluating the effects of cold compression on post-operative outcomes. Of the seven randomized trials evaluated, five concluded that cold compression therapy was superior to alternative treatment modalities for improving clinical outcomes after knee replacement surgery. ${ }^{2,30-33}$ In this procedure, the operative technique is standardized, surgical tissue damage is extensive, intraoperative blood loss is high, and post-operative edema and pain are severe. A well-defined randomized controlled trial in this model could provide the clear evidence needed to guide decisions regarding the clinical application of cold and compression in the post-operative setting.

\section{Disclosure}

The author reports no conflicts of interest in this work.

\section{References}

1. Meeusen R, Lievens P. The use of cryotherapy in sports injuries. Sports Med. 1986;3:398-414.

2. Kullenberg B, Ylipaa S, Soderlund K, Resch S. Postoperative cryotherapy after total knee arthroplasty: a prospective study of 86 patients. J Arthroplasty. 2006;21:1175-1179.

3. Raynor MC, Pietrobon R, Guller U, Higgins LD. Cryotherapy after ACL reconstruction: a meta-analysis. J Knee Surg. 2005;18:123-129.

4. Bleakley C, McDonough S, MacAuley D. The use of ice in the treatment of acute soft-tissue injury: a systematic review of randomized controlled trials. Am J Sports Med. 2004;32:251-261.

5. Collins NC. Is ice right? Does cryotherapy improve outcome for acute soft tissue injury? Emerg Med J. 2008;25:65-68.

6. Hubbard TJ, Aronson SL, Denegar CR. Does Cryotherapy Hasten Return to Participation? A Systematic Review. J Athl Train. 2004;39:88-94.

7. Hubbard TJ, Denegar CR. Does Cryotherapy Improve Outcomes With Soft Tissue Injury? J Athl Train. 2004;39:278-279.

8. Schroder D, Passler HH. Combination of cold and compression after knee surgery. A prospective randomized study. Knee Surg Sports Traumatol Arthrosc. 1994;2:158-165.

9. Wright JG, Araki CT, Belkin M, Hobson RW 2nd. Postischemic hypothermia diminishes skeletal muscle reperfusion edema. J Surg Res. 1989;47:389-396.

10. Ohkoshi Y, Ohkoshi M, Nagasaki S, Ono A, Hashimoto T, Yamane S. The effect of cryotherapy on intraarticular temperature and postoperative care after anterior cruciate ligament reconstruction. Am J Sports Med. 1999;27:357-362.

11. Ho SS, Coel MN, Kagawa R, Richardson AB. The effects of ice on blood flow and bone metabolism in knees. Am J Sports Med. 1994;22:537-540.

12. Knight KL, Londeree BR. Comparison of blood flow in the ankle of uninjured subjects during therapeutic applications of heat, cold, and exercise. Med Sci Sports Exerc. 1980;12:76-80.
13. Thorsson O, Lilja B, Ahlgren L, Hemdal B, Westlin N. The effect of local cold application on intramuscular blood flow at rest and after running. Med Sci Sports Exerc. 1985;17:710-713.

14. McMaster WC, Liddle S. Cryotherapy influence on posttraumatic limb edema. Clin Orthop Relat Res. 1980:283-287.

15. Meeusen R, van der Veen P, Joos E, Roeykens J, Bossuyt A, De Meirleir K. The influence of cold and compression on lymph flow at the ankle. Clin J Sport Med. 1998;8:266-271.

16. Chleboun GS, Howell JN, Baker HL, et al. Intermittent pneumatic compression effect on eccentric exercise-induced swelling, stiffness, and strength loss. Arch Phys Med Rehabil. 1995;76:744-749.

17. Ko DS, Lerner R, Klose G, Cosimi AB. Effective treatment of lymphedema of the extremities. Arch Surg. 1998;133:452-458.

18. Barlas D, Homan CS, Thode HC Jr. In vivo tissue temperature comparison of cryotherapy with and without external compression. Ann Emerg Med. 1996;28:436-439.

19. Merrick MA, Knight KL, Ingersoll CD, Potteiger JA. The effects of ice and compression wraps on intramuscular temperatures at various depths. J Athl Train. 1993;28:236-245.

20. Sloan JP, Hain R, Pownall R. Clinical benefits of early cold therapy in accident and emergency following ankle sprain. Arch Emerg Med. 1989;6:1-6.

21. Wilkerson GB, Horn-Kingery HM. Treatment of the inversion ankle sprain: comparison of different modes of compression and cryotherapy. J Orthop Sports Phys Ther. 1993;17:240-246.

22. Barber FA, McGuire DA, Click S. Continuous-flow cold therapy for outpatient anterior cruciate ligament reconstruction. Arthroscopy. 1998;14:130-135.

23. Brandsson S, Rydgren B, Hedner T, et al. Postoperative analgesic effects of an external cooling system and intra-articular bupivacaine/ morphine after arthroscopic cruciate ligament surgery. Knee Surg Sports Traumatol Arthrosc. 1996;4:200-205.

24. Cohn BT, Draeger RI, Jackson DW. The effects of cold therapy in the postoperative management of pain in patients undergoing anterior cruciate ligament reconstruction. Am J Sports Med. 1989;17:344-349.

25. Dervin GF, Taylor DE, Keene GC. Effects of cold and compression dressings on early postoperative outcomes for the arthroscopic anterior cruciate ligament reconstruction patient. J Orthop Sports Phys Ther. 1998;27:403-406.

26. Edwards DJ, Rimmer M, Keene GC. The use of cold therapy in the postoperative management of patients undergoing arthroscopic anterior cruciate ligament reconstruction. Am J Sports Med. 1996;24:193-195.

27. Konrath GA, Lock T, Goitz HT, Scheidler J. The use of cold therapy after anterior cruciate ligament reconstruction. A prospective, randomized study and literature review. Am J Sports Med. 1996;24:629-633.

28. Gibbons CE, Solan MC, Ricketts DM, Patterson M. Cryotherapy compared with Robert Jones bandage after total knee replacement: a prospective randomized trial. Int Orthop. 2001;25:250-252.

29. Healy WL, Seidman J, Pfeifer BA, Brown DG. Cold compressive dressing after total knee arthroplasty. Clin Orthop Relat Res. 1994:143-146.

30. Levy AS, Marmar E. The role of cold compression dressings in the postoperative treatment of total knee arthroplasty. Clin Orthop Relat Res. 1993:174-178.

31. Morsi E. Continuous-flow cold therapy after total knee arthroplasty. J Arthroplasty. 2002;17:718-722.

32. Scarcella JB, Cohn BT. The effect of cold therapy on the postoperative course of total hip and knee arthroplasty patients. Am J Orthop. 1995;24:847-852.

33. Webb JM, Williams D, Ivory JP, Day S, Williamson DM. The use of cold compression dressings after total knee replacement: a randomized controlled trial. Orthopedics. 1998;21:59-61.

34. Mora S, Zalavras CG, Wang L, Thordarson DB. The role of pulsatile cold compression in edema resolution following ankle fractures: a randomized clinical trial. Foot Ankle Int. 2002;23:999-1002.

35. Stockle U, Hoffmann R, Schutz M, von Fournier C, Sudkamp NP, Haas N. Fastest reduction of posttraumatic edema: continuous cryotherapy or intermittent impulse compression? Foot Ankle Int. 1997;18:432-438. 
36. Singh H, Osbahr DC, Holovacs TF, Cawley PW, Speer KP. The efficacy of continuous cryotherapy on the postoperative shoulder: a prospective, randomized investigation. J Shoulder Elbow Surg. 2001;10:522-525.

37. Speer KP, Warren RF, Horowitz L. The efficacy of cryotherapy in the postoperative shoulder. J Shoulder Elbow Surg. 1996;5:62-68.

38. Schulz KF, Chalmers I, Altman DG. The landscape and lexicon of blinding in randomized trials. Ann Intern Med. 2002;136:254-259.

39. Turner JA, Deyo RA, Loeser JD, Von Korff M, Fordyce WE. The importance of placebo effects in pain treatment and research. JAMA. 1994;271:1609-1614.
40. Warren TA, McCarty EC, Richardson AL, Michener T, Spindler KP. Intra-articular knee temperature changes: ice versus cryotherapy device. Am J Sports Med. 2004;32:441-445.

41. Dahl J, Li J, Bring DK, Renstrom P, Ackermann PW. Intermittent pneumatic compression enhances neurovascular ingrowth and tissue proliferation during connective tissue healing: a study in the rat. J Orthop Res. 2007;25:1185-1192.

Open Access Journal of Sports Medicine

\section{Publish your work in this journal}

Open Access Journal of Sports Medicine is an international, peer-reviewed, open access journal publishing original research, reports, reviews and commentaries on all areas of sports medicine. The manuscript management system is completely online and includes a very quick and fair peer-review system.
Visit http://www.dovepress.com/testimonials.php to read real quotes from published authors. 